\title{
Psychiatrists' attitudes to physical examination of new out-patients with a major depressive disorder
}

\author{
A. C. Mitchell, E. M. McCabe and K. W. Brown
}

\begin{abstract}
This survey examined Scottish psychiatrists' attitudes to physical examination and appropriate investigations in the routine assessment of new out-patients with a major depressive disorder. A discrepancy exists between current opinion towards and actual practice of physical examination in the assessment of new outpatients with depression. Numerous obstacles to performing investigations were identified including lack of time, inadequate consulting rooms, lack of equipment and lack of chaperon. The many obstacles identfified are considerable but not insurmountable. Missed diagnoses may have adverse consequences for patients as well as medico-legal implications.
\end{abstract}

Should psychiatrists do physicals? This question has not been resolved despite three decades of debate. The issue is important because of the potential harm to patients and the medico-legal consequences of missed organic pathology.

Psychiatric textbooks discuss the issue. A British text (Maguire, 1993) makes little mention of physical examination as part of the diagnostic interview. It does not discuss who should perform the examination, or the difficulties surrounding examination of out-patients. However, it does suggest that there should be a routine enquiry into the patient's recent health to screen for physical disorders. Another British text (Gelder et al, 1993) states that the psychiatrist should always determine what physical examination is necessary, ensure that it has been done adequately by the referring doctor, or arrange to have it done by himself or a deputy.

In contrast, a major American text (Hollander \& Wells, 1985) has a five page subsection on medical assessment in psychiatric practice. During the introduction the authors comment that significant medical disorders are frequently found in psychiatric patients and state "for most psychiatric patients, medical assessment is an essential component of the diagnostic evaluation". Another American text (Nurcombe \& Gallagher, 1986) strongly advocates that psychiatrists should perform examinations. It highlights reorganisation of services which may result in psychiatrists having more primary medical responsibility and the risks of assuming that the referring physician has examined the patient. It also suggests that physical examination may improve the doctor-patient relationship as a result of increased trust from the patient following perceived 'appropriate' investigation of their complaints. The differing advice may reflect the differences in primary care and referral practices in the two countries.

Physical examination is important because of the high prevalence of physical illness in psychiatric patients. Koranyi (1979) found that $43 \%$ of psychiatric out-patients suffered from one or more physical illness, half of which were unknown to the patient and referring physician. The study also demonstrated that in $20 \%$ of the physically ill, the undiagnosed somatic disorder was the sole cause of the psychiatric symptoms. The highest rates of undetected illness were not unexpectedly in the self-referral and social agency groups at $84 \%$, but even hospital physicians missed $32 \%$ of illnesses. Other studies of psychiatric patients detected rates of significant physical illness between 23.5 and $49 \%$, of which 5 to $42 \%$ were considered directly responsible for the psychiatric symptoms (Davies, 1965; Maguire \& Granville-Grossman, 1968; Hall et al, 1978; Koranyi, 1979).

In 1978. Patterson surveyed 155 American psychiatrists about their individual practices regarding physical examination. None of the respondents $(n=94)$ routinely performed physical examinations on new out-patients, and only 16 (17\%) sought them. Reasons for not examining patients included: lack of time; perceived paucity of physical signs; dislike of examination; and low confidence in clinical skills.

The authors are not aware of any recent research, nor any previous British studies on this subject. We therefore surveyed the attitudes of Scottish psychiatrists to physical examination and blood tests as part of the routine assessment of new out-patients diagnosed as having a major depressive disorder. Our aims were to establish whether routine physical examination and blood 
tests are considered necessary by Scottish psychiatrists, whether these investigations are performed and whether there were any obstacles to performing the investigations.

\section{The study}

We acquired a list of psychiatrists approved under Section 20 of the Mental Health (Scotland) Act 1984 who were currently practising in Scotland. A postal questionnaire was sent to all consultants (non-consultants were excluded) in January 1995, with a second mailing two months later.

Data were analysed using SPSS for Windows. Chi-squared and Fisher's exact test were used to test the association between opinion and reported practice, specialty, gender and experience.

\section{Findings}

Three hundred and twenty questionnaires were sent; 20 questionnaires were excluded either because the respondents were not consultants, were retired or had moved post, leaving a denominator of 300 . The response rate was 244 (81\%). Their specialities were: general adult psychiatry $(81,33 \%)$, mixed posts $(67,28 \%)$, child/adolescent $(33,14 \%)$, old age psychiatry $(22,9 \%)$ and the remainder from all the other sub-specialities.

One hundred and eighty-three respondents (75\%) considered that physical examinations were sometimes necessary, 37 (15\%) always necessary and 21 (9\%) never necessary. Appropriate investigations were considered sometimes necessary by $194(80 \%)$, always necessary by 27 (11\%), and never necessary by $16(7 \%)$. The most common reasons for performing a physical examination were physical complaints by the patient $176(72 \%)$, a history of physical illness $138(57 \%)$ and associated alcohol misuse 120 (49\%). The most common reasons for blood tests were associated with alcohol misuse $(164,67 \%)$, physical complaints $(153,63 \%)$ and a history of

Table 1. Indications for physical examinations and blood tests

\begin{tabular}{lll}
\hline Indication & $\begin{array}{l}\text { Physical } \\
\text { examination } \\
\boldsymbol{n}(\%)\end{array}$ & $\begin{array}{l}\text { Blood tests } \\
\boldsymbol{n}(\%)\end{array}$ \\
\hline Physical complaints & $176(72)$ & $153(63)$ \\
History of physical illness & $138(57)$ & $118(48)$ \\
Associated alcohol misuse & $120(49)$ & $164(67)$ \\
Not done by GP & $79(32)$ & $76(31)$ \\
Current drug therapy & $47(19)$ & $69(28)$ \\
Medico-legal reasons & $40(16)$ & $34(14)$ \\
Other & $38(16)$ & $35(14)$ \\
\hline
\end{tabular}

physical illness $(118,48 \%)$ (see Table 1). Several respondents stated that they would also perform investigations in patients over 55 years and when planning drug therapy for children.

A sizeable proportion of psychiatrists $(66,27 \%)$ considered that it was not part of their role to perform a physical examination, but there were no significant differences between sub-specialities. The main reasons given for not examining or taking blood from a patient included presumed previous investigation by the general practitioner $(200,82 \%)$, and anticipated low rate of abnormalities $(76,31 \%$ ) (see Table 2).

Several obstacles to performing physical examination or blood tests were identified, most frequently lack of time and type of consulting room. Other common obstacles encountered included no physical tray, no examination couch and no venepuncture equipment (Table 3).

Psychiatrists were also asked when they had last performed physical examinations and blood tests. Fifty-eight (24\%) had examined patients in the previous month, $74(30 \%)$ in the previous year, $69(28 \%)$ over one year ago and $24(10 \%)$ stated they had never examined a patient. The equivalent figures for blood taking were $(66$, $27 \%),(62,25 \%),(76,31 \%)$ and $(14,6 \%)$.

There were no significant differences in attitudes or practice in male or female psychiatrists. Old age psychiatrists were more likely to perform examinations $(P<0.004)$ and blood tests $(P<0.000)$ between sub-specialities. Length of time as a consultant did not produce significant differences in attitudes towards examination, but longer serving consultants were more likely to consider blood tests necessary $(P<0.003)$, but were not more likely to perform blood tests.

\section{Comment}

This study shows that the majority of Scottish psychiatrists consider physical examination an important part of the routine assessment of new out-patients with a depressive disorder. Despite this, physical examination is performed relatively infrequently due to a number of obstacles

Table 2. Reasons for not performing physical examination and blood tests

\begin{tabular}{lll}
\hline & $\begin{array}{l}\text { Physical } \\
\text { examination } \\
n(\%)\end{array}$ & $\begin{array}{l}\text { Blood tests } \\
n(\%)\end{array}$ \\
\hline Reason & $200(82)$ & $201(82)$ \\
\hline GP already investigated & $76(31)$ & $64(26)$ \\
Low yield of abnormalities & $66(27)$ & $41(17)$ \\
Not psychiatrist's role & $47(19)$ & $16(7)$ \\
Not confident in skills & $25(10)$ & $16(7)$ \\
Invasion of patient's privacy & $25(19)$ & $40(16)$ \\
Other & $46(16)$
\end{tabular}


Table 3. Obstacles to performing intended investigation

\begin{tabular}{lll}
\hline & $\begin{array}{l}\text { Physical } \\
\text { examination } \\
n(\%)\end{array}$ & $\begin{array}{l}\text { Blood fests } \\
\boldsymbol{n}(\%)\end{array}$ \\
\hline Obstacle & $149(61)$ & $104(43)$ \\
\hline Time & $133(55)$ & $75(31)$ \\
Type of consulting room & $106(43)$ & $54(22)$ \\
No physical tray & $94(39)$ & $16(7)$ \\
No chaperon & $93(38)$ & $27(11)$ \\
No couch & $40(16)$ & $88(36)$ \\
No venepuncture equipment & $44(14)$ & $5(2)$ \\
Patient's gender & $20(8)$ & $3(1)$ \\
Belleve patient embarrassed & 20 \\
Belleve patient would refuse & $12(5)$ & $8(3)$ \\
Uncomfortable for doctor & $8(3)$ & $3(1)$ \\
Other & $29(12)$ & $20(8)$ \\
\hline
\end{tabular}

and erroneous beliefs. These findings mirror an earlier American study (Patterson, 1978).

The most common reason given for not performing a physical examination was 'general practitioner had already investigated'. Unless specified in the referral letter, this may be a dangerous assumption. Our experience is that referral letters rarely mention previous physical assessment implying that either no abnormalities were found, or that no examinations or investigations were performed. It is tempting to assume the former, however reality may suggest that eight minute consultations leave little time for a thorough physical examination.

The belief that examination and investigation would yield few abnormalities was widely held. Previous research does not bear this out. Morbidity in psychiatric clinic patients far surpassed the expected rate found in the general population, and the presence of a primary care physician did not protect the patient from unrecognized physical illness (Hall et al, 1978).

Competence in physical examination is a requirement of the current MRCPsych examinations. Despite this, we found that almost $20 \%$ of respondents did not feel competent in physical examination.

There were a number of obstacles identified, lack of time and facilities being the main reasons stated. The move to community-based services with assessment in the patient's home adds to the difficulties, especially when this necessitates the carrying of equipment and the presence of a chaperon may be required.

One respondent remarked that 'potential obstacles should be anticipated and overcome'. Various measures might help. If all patients cannot be examined, those at high risk of having physical abnormalities may be identified by the use of symptom checklists. One such checklist placed patients in high and low risk groups in which the yield of biochemical abnormalities was
60 and 3\% respectively (Hall et al, 1978). Clinics should be equipped and staffed appropriately, though one respondent's requests for equipment had been ignored. A referral protocol could be agreed with the local general practitioners where an agreed set of physical investigations were performed prior to referral or an undertaking that requested examinations would be done at the suggestion of the psychiatrist. Nursing staff could perform specific tasks such as blood pressure measurement, urinalysis and blood tests.

The prevalence of physical illness reported by Maguire \& Granville-Grossman (1968) led them to conclude that the establishment of psychiatric units in general hospitals was necessary to maintain high standards of care for the mentally ill. Psychiatric services have moved from being hospital-based to the community. This move should not compromise the standard of care available to patients. Careful planning of service delivery can overcome many of the obstacles identified in this study.

\section{References}

DAvies, W. D. (1965) Physical illness in psychiatric outpatients. British Journal of Psychiatry, 111, 27-37.

GeLDER, M., GATH, D. \& MAYOU, R. (1993) Interviewing, clinical examination, and record keeping. In Oxford Textbook of Psychiatry, pp. 37-74. Oxford: Oxford Medical Publications.

Hall, R. C. W., POPKINS, M. K., Deuval, R. A., et al (1978) Physical illness presenting as psychiatric disease Archives of General Psychiatry, 35, 1315-1320.

Hollander, M. \& Wels, C. E. (1985). Medical assessment in psychiatric practice. In Comprehensive Textbook of Psychiatry (4th edn), Vol. 1, (eds H. I. Kaplan \& B. I. Sadock), pp. 543-549. Baltimore, MD: Williams \& Wilkins.

KORANY, E. K. (1979) Morbidity and rate of undiagnosed physical illnesses in a psychiatric clinic population. Archives of General Psychiatry, 36, 414-419.

Maguire, G. P. (1993) The psychiatric interview. In Companion to Psychiatric Studies (eds R. E. Kendell \& A. K. Zealley), pp. 263-276. London: Churchill Livingstone.

- \& Granvile-Grossman, K. L. (1968) Physical illness in psychiatric patients. British Journal of Psychiatry, 116. 1365-1369.

Nurcombe, B. \& Gallagher, R. M. (1986) The Clinical Process in Psychiatry. Cambridge: Cambridge University Press.

PATterson, C. W. (1978) Psychiatrists and physical examinations: a survey. American Journal of Psychiatry, 136, 967-968.

A. C. Mitchell, Career Registrar, The State Hospital, Carstairs; E. M. McCabe, Staff Psychiatrists, Westbank Day Unit, Falkirk; and ${ }^{*}$ K. W. Brown, Consultant Psychiatrist, Central Scotland Healthcare, Bellsdyke Hospital, Bellsdyke Road, Larbert FK5 4SF

*Correspondence 